\title{
К ВОПРОСУ О НЕКОТОРЫХ ПРИЧИНАХ «ОМОЛОЖЕНИЯ» ПРОТЕСТНЫХ НАСТРОЕНИЙ В РОССИИ
}

\section{ON THE QUESTION OF POSSIBLE CAUSES OF «REJUVENATION» OF THE PROTEST MOODS IN RUSSIA}

\author{
В.В. Титов, Н.А. Самохвалов \\ V.V. Titov, N.A. Samohvalov \\ Финансовый университет при Правительстве Российской Федерации, \\ Россия, 125993, Москва, ул. Ленинградский проспект, 49 \\ Балаковский филиал Российской академии народного хозяйства и государственной службы \\ при Президенте Российской Федерации, \\ Россия, 413840, Саратовская область, г. Балаково, ул. Чапаева, 107 \\ Financial University under the Government of the Russian Federation, \\ 49, Leningradsky avenue, Moscow, 125993, Russia \\ Balakovo branch of RANEPA, 107 Chapaev St, Balakovo, Saratov region, 413840, Russia \\ E-mail: VVTitov@fa.ru; nikolai-samohvalov@yandex.ru
}

\begin{abstract}
Аннотация
В представленной статье авторы рассматривают молодежь в качестве базового элемента российской политики. Учитывая, что молодежь представляет собой один из стратегически важных ресурсов общества, от эффективности использования которого во многом определяется его жизнедеятельность, авторы акцентируют свое внимание на рассмотрении проблемных аспектов, стоящих перед молодежью России на современном этапе. При этом не без оснований отмечается, что молодое поколение граждан Российской Федерации, не получая конкретных предложений и механизмов по разрешению актуальных для них проблем со стороны органов государственной власти, вынуждено высказывать свою гражданскую позицию посредством организации протестного движения и непосредственного участия в нем. В контексте сказанного следует констатировать, что в последнее время молодежный протест находится в стадии интенсификации, а также расширяет свою социально-политическую повестку. В рамках данной статьи авторы уделили особое внимание некоторым причинам, лежащим в основе процесса «омоложения» протестных настроений в России.
\end{abstract}

\begin{abstract}
In this article, the authors consider youth as a basic element of Russian politics. Considering that youth is one of the hidden resources of society, the mobilization of which in many respects depends on its viability, the authors focus on consideration of the problematic aspects facing the youth of Russia at the present stage. At the same time, it is noted, not without reason, that the young generation of citizens of the Russian Federation, without receiving specific proposals and mechanisms for resolving issues that are relevant to them on the part of state authorities, are forced to express their civic position by organizing a protest movement and directly participating in it. In the context of what has been said, it should be noted that recently youth protest is in the stage of intensification, and is also expanding its socio-political agenda. In the framework of this article, the authors paid special attention to some of the reasons underlying the process of «rejuvenating» the protest moods in Russia.
\end{abstract}

Ключевые слова: молодежь, государство, государственная молодежная политика, молодежный протест.

Keywords: youth, state, state youth policy, youth protest. 
В окружающей действительности каждый из нас может вольно или невольно заметить попытки различных государственных структур и общественных организаций привлечь на свою сторону молодежь, «заразить» их своими идеями, тем самым сформировать такой «молодежный контент», который позволит им достичь стоящие перед ними цели и задачи. Стихийным образом, а порой и под строгим контролем с помощью определенных методик и моделей возникают различные группы и объединения, эксплуатирующие стремление молодых людей группироваться с себе подобными. К подобным группам и объединениям, к примеру, можно отнести отделения международных организаций, «молодежные» организации политических партий, религиозные организации и другие. К слову сказать, что в последний период времени пристальное внимание на молодежь обратила и православная церковь, которая раньше, казалось бы, не имела интересов в этом вопросе. В частности, появилось множество молодежных лагерей, в том числе и военнопатриотических, поддерживаемых православной церковью.

В контексте сказанного весьма интересным представляется следующий вопрос: почему все так заинтересовались проблемами молодежи, и почему все это актуализировалось именно сейчас? Чем так привлекательна молодежь для представителей политических сил современной России?

На наш взгляд, это объясняется следующими причинами:

1) Российское общество, находящееся на современном этапе развития, оказалось не в состоянии адекватно реагировать на проблемы представителей молодого поколения и формировать гибкую молодежную политику. Во многом это обусловлено тем, что обозначаемые на самых различных властных уровнях вопросы эффективной реализации государственной молодежной политики, к нашему глубокому сожалению, в настоящий момент времени не приобрели особое значение для органов государственного управления. Кроме того, кризисные явления, наблюдающиеся в экономике Российской Федерации на современном этапе, заставили государство искать возможные формы поддержания своей стабильности, тем самым игнорируя некоторые перспективные направления развития, к которым относится и молодежная политика. Подобное смещение вектора внимания в зону экономических проблем привело к тому, что молодежь была на протяжении достаточно долгого временного отрезка предоставлена сама себе, находясь вне интересов каких-либо структур, способных к реализации ее интересов.

2) Как в начале 90-х годов, так и сейчас молодежь двадцать первого столетия характеризуется отсутствием фундаментальных общественных ориентиров. По нашему мнению, это можно объяснить двумя основными тенденциями. Первая тенденция выражена в деструкции классических форм социального развития советской молодежи: комсомола, пионерской организации, молодежного спорта, ДОСААФ и неспособности при этом привести к созданию радикально новых механизмов молодежной политики в постсоветской России. Вторая тенденция заключается в том, что на уровне государства принимается целый ряд программ, таких как проект «Молодежь России», «Государственная концепция молодежной политики», призванных разрешить эту проблему. В них достаточно подробно излагаются насущные проблемы молодежи, которые действительно актуальны в молодежной среде, и предлагается целый ряд способов их решения в виде конкретной программы действий. Однако современная практика реализации подобных действий оставляет, мягко говоря, желать лучшего [Самохвалов, 2018, с. 479].

Активно вовлекать молодежь в свою деятельность стараются, в первую очередь, непосредственные акторы политического процесса России - политические партии. Подтверждением обозначенного нами утверждения выступает тот факт, что молодежная организация есть сейчас практически у каждой российской партии. Однако подобные молодежные организации политической ориентации выражают не интересы молодежи, а политические интересы конкретной партии, хотя лидеры партий постоянно утверждают обратное. Молодежь для политических партий сегодня выступает, скорее, неким субстратом, из которого формируется ее электорат в долгосрочной перспективе. У каждой партии имеет- 
ся свой собственный взгляд на практики работы с молодежью, выраженный в реализуемых ими «концепциях» и «программах» деятельности. Чтобы лучше представить себе сущность этих документов, приведем несколько выдержек из молодежных программ наиболее крупных политических партий.

Согласно молодежной программе партии «Единая Россия», «молодежь представляет собой ценнейший и уникальный ресурс любого общества, фундамент его дальнейшего существования и развития. Концепция государственной молодежной политики, предлагаемая данной партией, направлена на создание правовых, экономических, организационных и иных условий и гарантий для самореализации личности молодого человека» [Молодежная программа партии «Единая Россия», 2019].

Целью молодежной политики КПРФ является расширение политического влияния на молодежь. Подобная цель может быть достигнута только при целевой работе с молодежью. Для роста доверия молодежи к КПРФ необходимо реализовывать в нашей работе принцип «промежуточной полезности». Данный принцип заключается в том, что мы должны помогать молодежи в их борьбе за свои права, а не только обещать решение всех их социальных проблем» [Молодежная программа партии КПРФ, 2019].

Согласно молодежной программе партии ЛДПР, «в настоящее время в России отсутствует система государственной молодежной политики. Мы - молодежь России - открыто заявляем, что не позволим использовать себя в грязных политических играх. Мы за сильную и стабильную Россию, за истинный патриотизм, за молодость и перспективу! Мы против революций и их организаторов. И мы всегда готовы выйти на улицу и защитить нашу страну от безумных попыток устроить переворот и окончательно поставить наш народ на колени» [Молодежная программа партии ЛДПР, 2019].

По приведенным выше выдержкам становится очевидным, что молодежь выступает для партии ресурсом и орудием политической борьбы. Речь идет не о решении проблем молодежи как социально-демографической группы, а «расширении влияния» на нее, «вовлечении в классовую борьбу». Члены этих партий, конечно, будут возражать, но так и никак иначе все это выглядит со стороны. И это вполне логично, ведь целью любой политической партии является получение и удержание политической власти. А какими средствами - уже вопрос другой.

Подобное положение дел, когда молодежь используется для решения определенных задач соответствующими политическими субъектами с одновременным отсутствием должного внимания к их проблемам, в своей совокупности создает благоприятную конъюнктуру для формирования протестных настроений и ориентаций в молодежной среде. Протестный потенциал молодежи, а также его теоретико-методологические основания, особенности и последствия постоянно находятся в центре политического дискурса. В частности, они нашли свое отражение в трудах следующих исследователей: Г.И. Авцинова [Авцинова, 2015], Д.А. Аюшеева [Аюшеева, 2019], П.В. Бударин [Бударин, 2018], В.М. Барсегян [Барсегян, 2014], Ю.Ю. Галактионова [Галактионова, 2019], Ю.М. Головко [Головко, 2016], М.С. Грачева [Грачева, 2016], Е.Ю. Кирюхина [Кирюхина, 2014], Е.И. Ковтун [Ковтун, 2019], Д.А. Ластовкина [Ластовкина, 2015], П.А. Меркулов, Н.В. Проказина [Меркулов, Проказина 2017], А.В. Петрушина [Петрушина, 2012] и других.

Безусловно, протестные настроения в молодежной среде имели место всегда, однако их особенностью в России в настоящий период времени выступает усиливающаяся тенденция на «омоложение» протестным образом ориентированной молодежи.

Так, в частности, 27 июля 2019 г. в Москве состоялась крупнейшая за минувшие два года несанкционированная акция протеста. Поводом к ней послужил не допуск к выборам в Мосгордуму «независимых кандидатов», в частности Дмитрия Гудкова и сторонницы Алексея Навального Любови Соболь.

По информации властей, в митинге приняли участие свыше трѐх тысяч человек. Однако число протестующих было намного больше, учитывая количество задержанных, которое перевалило за тысячу человек (по официальным данным - 1074). Скорее всего, 
27 июля 2019 г. днѐм в центре города собрались не менее пяти тысяч человек. Вечером того же дня несколько сотен активистов по призыву оппозиционных структур пришли на Трубную площадь [Титов, Самохвалов 2019, с. 52].

Прошедшая акция протеста вновь дала явный повод говорить о проблеме «омоложения» сторонников внесистемной оппозиции. Ядро митингующих составили молодые граждане в возрасте 16-22 лет. Как нам представляется, главным объяснением того, что протестное ядро составили главным образом совсем молодые люди, является отсутствие достаточного жизненного опыта и образования у данных представителей молодого поколения, кроме того, данная категория имеет весьма слабое представление о политических реалиях, в которых находится Россия.

В частности, на тренде по омоложению протестного движения в отечественной социально-политической практике акцентирует свое внимание директор Центра молодежных исследований НИУ ВШЭ Е. Омельченко. В контексте сказанного Е. Омельченко отмечает следующее: «протест действительно помолодел, это было заметно уже в 2017-2018 году, когда писали, что на улицы вышла "школота $\rightarrow$.

Солидаризировавшись с обозначенной позицией Е. Омельченко, приходим к выводу, что к возможным обстоятельствам и причинам, послужившим «омоложению» российского протестного движения можно отнести следующие:

Во-первых, для современных молодых людей очень важно участие в низовых гражданских практиках, которые вовсе не обязательно напрямую связаны с политикой. Это могут быть экологические проекты, зоозащита, помощь больным людям, людям, которые находятся в трудной жизненной ситуации и многое другое. Для молодых людей очень важно, что это их собственные низовые гражданские практики, они независимы от государства.

Во-вторых, очень важные для нынешней молодежи понятия и ценности - это принятие, понимание, разделенность, включенность, сопричастность и принадлежность. Официальная политика не может ничего из этого дать, потому что молодые люди не могут полноценно участвовать в политических процессах, принимать решения и влиять на результат и выступать в качестве непосредственного актора социально-политических процессов. Поэтому они стремятся формировать собственную независимую повестку и собственную среду.

В-третьих, для молодых людей также очень важна эмоциональная сторона и особенно обострено чувство справедливости. На этом фундаменте формируется своего рода низовой гражданский патриотизм в противоположность существующему милитаристскому патриотизму, который власть навязывает сверху различными методами и средствами путем оказания воздействия на молодежь.

Весьма интересным, как нам представляется, выступает тот факт, что часть молодых людей, принимавших непосредственное участие в митингах, и вовсе лишена права ходить на избирательный участок. Отсюда возникает вопрос: с какой целью они вышли на акции протеста?

Считаем, что отчасти ответ кроется в большой популярности яркого представителя так называемой внесистемной оппозиции Алексея Навального в молодежной среде, а именно популяризация оппозиционера в интернет-контенте и его эффективном использовании в качестве инструмента воздействия, основным пользователем которого выступает именно молодежь.

Наиболее ярким свидетельством о молодежном фундаменте целевой аудитории Алексея Навального выступает волна несанкционированных властями акций, прошедших весной 2017 года после выхода фильма «Он вам не Димон» фонда борьбы с коррупцией, созданного указанным выше оппозиционером. Несовершеннолетних лиц, которые принимали участие в тех акциях, прозвали «навальнятами». Абсолютно искренне и с высокой степенью серьезности на митингах они рассказывали о том, как чудесным образом преоб- 
разится Россия, если Владимир Путин покинет пост президента Российской Федерации [Платонов, 2018, с. 24].

Памятуя о тех событиях, что в центре Москвы опять соберутся юные оппозиционеры, правоохранительные органы предупредили о грозящих штрафах, административных apecтах, а также о предусмотренной законом мере ответственности за уклонение от воинской повинности. Кроме того, весьма кстати в парке Горького был организован День гамбургера, который с большой вероятностью оттянул тысячи «сопереживающих» Навальному молодых людей.

Продолжая суждения о причинах, которые влияют на процесс «омоложения» протестного движения в России, считаем необходимым акцентировать внимание на том факте, что за время пребывания В.В. Путина в должности первого лица государства в России выросло поколение, которое не помнит другого руководителя государства. Конечно, можно сказать, что в период 2008-2012 гг. пост президента РФ занимал Дмитрий Анатольевич Медведев, однако даже молодежь понимает, что это было определенной формальностью.

Современная молодѐжь выросла в достаточно благополучное время. Она не пережила масштабных социально-политических потрясений, не помнит про полуголодные девяностые годы, не представляет, что такое сепаратизм, гражданская война [Руденкин, 2017, c. 28].

Тем самым неотягощѐнное трагедиями сознание позволяет более уверенно смотреть в будущее без страха возвращения в прошлое, который по-прежнему навязывается сверху. Власть и федеральные СМИ продолжают бессовестно спекулировать на теме 1990-х годов. Дескать, если у руля страны встанут другие люди, то Россия вновь погрузится в хаос первых лет после распада СССР [Челпанова, 2014, с. 59].

Следует констатировать, что в подавляющем большинстве молодѐжь не в состоянии сформулировать причины негатива к первому лицу и представить какую-либо альтернативную модель развития российской государственности. Скорее всего, в сознании подрастающего поколение является дикостью сам факт, что один человек находится у власти 20 лет и будет править страной по меньшей мере до 2024 года. При этом кажется весьма парадоксальным, что именно Владимиру Путину юные оппозиционеры обязаны своим благополучным прошлым и настоящим.

Растущее недовольство молодѐжи президентом вызвано, прежде всего, нежеланием переваривать господствующий в РФ принцип несменяемости власти. Ярким подтверждением данного обстоятельства служит тот факт, что молодежь в процессе общественного обсуждения поправок к Основному закону государства высказалась категорически против «обнуления» президентских сроков действующего главы государства.

Таким образом, суммируя вышесказанное, становится очевидным, что в России давно стала очевидной необходимость перемен в социально-политической сфере с целью разрешения основных проблем, стоящих перед молодым поколением. Несмотря на это, в реальности мы видим, что Правительство РФ отказывается проводить работу над ошибками, а оппозиция не предлагает какой-либо внятной программы действий, кроме разрушения сложившейся социально-политической системы, которая пусть и порочна, но находится в более-менее работоспособном состоянии, тем самым просто использует молодежь в качестве инструмента для решения стоящих перед ней целей и задач. Именно поэтому современная молодежь, во многом полагаясь исключительно на собственные силы и возможности, пытается обратить на себя фокус внимания властных структур в России, в том числе посредствам осуществления молодежного протестного движения.

\section{Список литературы}

1. Авцинова Г.И. 2015. Протестный потенциал российской молодежи: парадигмы исследования и политическая практика. PolitBook. 1: 111-126.

2. Аюшеева Д.А. 2019. Участие молодежи в протестных акциях в современной России как способ самоидентичности. Управленческое консультирование. 6: 147-153. 
3. Бударин П.В. 2018. Особенности вовлечения подростков к участию протестной деятельности современной оппозицией в РФ. Теории и проблемы политических исследований. 5А: $230-237$.

4. Барсегян В.М. 2014. Формы и факторы политической активности молодежи: классические концепции и современные исследования. Гуманитарные и социально-экономические науки. 4 (77): $120-124$.

5. Галактионова Ю.Ю. 2019. Политическое протестное поведение современной российской молодежи. Master's Journal. 1: 119-126.

6. Головко Ю.М. 2016. Реализация принципа «российской мечты» для молодежи или существует ли необходимость участвовать в акциях протеста?. Вестник Башкирского института социальных технологий. 3 (32): 59-65.

7. Грачева М.С. 2016. Политический протест современной молодежи в концептуальном осмыслении западной политологии. Вестник Московского государственного областного университета. Серия: История и политические науки. 5: 138-142.

8. Кирюхина Е.Ю. 2014. Эволюция молодежного политического протеста в современной России: от уличных акций к социальным сетям. Вопросы политологии. 2 (14): 38-45.

9. Ковтун Е.И. 2019. Специфика современных молодежных протестных движений. Вопросы политологии. 4 (44): 712-721.

10. Ластовкина Д.А. 2015. Современные формы протеста: к постановке вопроса. Вопросы территориального развития. 6 (26): 3.

11. Меркулов П.А., Проказина Н.В. 2017. Методологические подходы к анализу протестной деятельности молодежи. Среднерусский вестник общественных наук. 1: 15-23.

12. Молодежная программа партии «Единая Россия». URL: http://www.old.edinros.ru (дата обращения: 25.12.2019).

13. Молодежная программа партии КПРФ. URL: http:// www.kprf.ru/party_live/55847 (дата обращения: 25.12.2019).

14. Молодежная программа партии ЛДПР. URL: http:// www.ldpr.ru/molodvigenie2 (дата обращения: 25.12.2019).

15. Платонов К.А. 2018. Цифровой протест в социальной сети: специфика молодежной аудитории. Молодежная Галактика. 15: 19-26.

16. Петрушина А.В. 2012. Протестное участие молодежи в современном российском обществе. Автореф. дис. ... канд. социол. наук. Тула, 27.

17. Руденкин Д.В. 2017. Протестные настроения российской молодежи через год после митингов. Социодинамика. 2: 23-33.

18. Самохвалов Н.А. 2018. Социальные и политические ориентиры российской молодежи. В кн: Политика развития, государство и мировой порядок, Материалы VIII Всероссийского конгресса политологов. Под общ. ред. О.В. Гаман-Голутвиной, Л.В. Сморгунова, Л.Н. Тимофеевой. Москва, Изд-во «Аспект-Пресс»: 479-480.

19. Титов В.В., Самохвалов Н.А. 2019. Анализ социально-политических ценностей молодежи на современном этапе развития российского общества. Азимут научных исследований: экономика и управление. 1 (26): 51-54.

20. Челпанова Д.Д. 2014. Протестный потенциал студенческой молодежи юга России. Научная мысль Кавказа. 1 (77): 55-62.

\section{References}

1. Avcinova G.I. 2015. Protestnyj potencial rossijskoj molodezhi: paradigmy issledovanija i politicheskaja praktika. PolitBook. 1: 111-126.

2. Ajusheeva D.A. 2019. Uchastie molodezhi v protestnyh akcijah v sovremennoj Rossii kak sposob samoidentichnosti. Upravlencheskoe konsul'tirovanie. 6: 147-153.

3. Budarin P.V. 2018. Osobennosti vovlechenija podrostkov k uchastiju protestnoj dejatel'nosti sovremennoj oppoziciej v RF. Teorii i problemy politicheskih issledovanij. 5A: 230-237.

4. Barsegjan V.M. 2014. Formy i faktory politicheskoj aktivnosti molodezhi: klassicheskie koncepcii i sovremennye issledovanija. Gumanitarnye i social'no-jekonomicheskie nauki. 4 (77): 120-124.

5. Galaktionova Ju.Ju. 2019. Politicheskoe protestnoe povedenie sovremennoj rossijskoj molodezhi. Master's Journal. 1: 119-126. 
6. Golovko Ju.M. 2016. Realizacija principa «rossijskoj mechty» dlja molodezhi ili sushhestvuet li neobhodimost' uchastvovat' v akcijah protesta? Vestnik Bashkirskogo instituta social'nyh tehnologij. 3 (32): 59-65.

7. Gracheva M.S. 2016. Politicheskij protest sovremennoj molodezhi v konceptual'nom osmyslenii zapadnoj politologii. Vestnik Moskovskogo gosudarstvennogo oblastnogo universiteta. Serija: Istorija i politicheskie nauki. 5: 138-142.

8. Kirjuhina E.Ju. 2014. Jevoljucija molodezhnogo politicheskogo protesta v sovremennoj Rossii: ot ulichnyh akcij k social'nym setjam. Voprosy politologii. 2 (14): 38-45.

9. Kovtun E.I. 2019. Specifika sovremennyh molodezhnyh protestnyh dvizhenij. Voprosy politologii. 4 (44): 712-721.

10. Lastovkina D.A. 2015. Sovremennye formy protesta: k postanovke voprosa. Voprosy territorial'nogo razvitija. 6 (26): 3 .

11. Merkulov P.A., Prokazina N.V. 2017. Metodologicheskie podhody k analizu protestnoj dejatel'nosti molodezhi. Srednerusskij vestnik obshhestvennyh nauk. 1: 15-23.

12. Molodezhnaja programma partii «Edinaja Rossija». URL: http://www.old.edinros.ru (data obrashhenija: 25.12.2019).

13. Molodezhnaja programma partii KPRF. URL: http:// www.kprf.ru/party_live/55847 (data obrashhenija: 25.12.2019).

14. Molodezhnaja programma partii LDPR. URL: http:// www.ldpr.ru/molodvigenie2 (data obrashhenija: 25.12.2019).

15. Platonov K.A. 2018. Cifrovoj protest v social'noj seti: specifika molodezhnoj auditorii. Molodezhnaja Galaktika. 15: 19-26.

16. Petrushina A.V. 2012. Protestnoe uchastie molodezhi v sovremennom rossijskom obshhestve. Avtoref. dis. ... kand. sociol. nauk. Tula, 27.

17. Rudenkin D.V. 2017. Protestnye nastroenija rossijskoj molodezhi cherez god posle mitingov. Sociodinamika. 2: 23-33.

18. Samohvalov N.A. 2018. Social'nye i politicheskie orientiry rossijskoj molodezhi. V kn: Politika razvitija, gosudarstvo i mirovoj porjadok Materialy VIII Vserossijskogo kongressa politologov. Pod obshh. red. O.V. Gaman-Golutvinoj, L.V. Smorgunova, L.N. Timofeevoj. Moskva, Izd-vo «AspektPress», 479-480.

19. Titov V.V., Samohvalov N.A. 2019. Analiz social'no-politicheskih cennostej molodezhi na sovremennom jetape razvitija rossijskogo obshhestva. Azimut nauchnyh issledovanij: jekonomika i upravlenie. 1 (26): 51-54.

20. Chelpanova D.D. 2014. Protestnyj potencial studencheskoj molodezhi juga Rossii. Nauchnaja mysl' Kavkaza. 1 (77): 55-62.

\section{Ссылка для цитирования статьи Reference to article}

Титов В.В., Самохвалов Н.А. 2020. К вопросу о некоторых причинах «омоложения» протестных настроений в России. Via in tempore. История. Политология, 47(1): 211-217.

DOI 10.18413/2687-0967-2020-47-1-211-217

Titov V.V., Samohvalov N.A. 2020. On the question of possible causes of «rejuvenation» of the protest moods in Russia. Via in tempore. History and political science, 47(1): 211-217 (in Russian).

DOI 10.18413/2687-0967-2020-47-1-211-217 